\title{
Wiring and plumbing in the brain
}

\author{
Jean Rossier* \\ Laboratoire de Neurobiologie CNRS, Ecole Supérieure de Physique et de Chimie Industrielles, 75231 Paris Cedex 05, France. \\ *Correspondence: jean.rossier@espci.fr
}

\section{A commentary on}

Stimulus-induced changes in blood flow and 2-deoxyglucose uptake dissociate in ipsilateral somatosensory cortex.

byDevorA., Hillman, E.M., Tian, P., Waeber, C., Teng, I.C., Ruvinskaya, L., Shalinsky, M.H., Zhu, H., Haslinger, R.H., Narayanan, S.N., Ulbert, I., Dunn, A.K., Lo, E.H., Rosen, B.R., Dale, A.M., Kleinfeld, D., and Boas, D.A. (2008). J. Neurosci. 28, 14347-14357.

Brain metabolism dictates the polarity of astrocyte control over arterioles

by Gordon, G.R.C., Choi, H.B., Rungta, R.L., Ellis-Davies, G.C.R., and MacVicar, B.A. (2008). Nature 456, 745-750.

Anticipatory haemodynamic signals in sensory cortex not predicted by local neuronal activity

by Sirotin, Y.B., and Das, A. (2009). Nature, 457, 475-479.

No one with common sense would believe that in a house, water movements in pipes could tell you how many lamps are on and how much fuel is used for heating. Surprisingly most neuroscientists are convinced that in the brain monitoring local cerebral blood flow (CBF) what I call plumbing, is a reliable surrogate method to localize electrical neuronal activity and monitor metabolic events. This is usually done by functional magnetic resonance imaging (fMRI) a technique that measures haemodynamic changes. In fMRI, the blood-oxygen-level-dependent (BOLD) signal resulting from the paramagnetic properties of deoxyhaemoglobin in red blood cells is measured with precise local and time resolution. In most neuroimaging fMRI studies, activation of the brain with cognitive tasks or sensory stimuli results in a local functional hyperaemia, most of the time accompanied by an increase in the local field potentials (LFP) (Logothetis, 2008). How activation of the brain transmutes in functional hyperaemia is the topic of intense debate among neuroscientists with two hypothesis, the "metabolic" and the "neurogenic" (Estrada and DeFelipe, 1998; Hamel, 2006).

The metabolic hypothesis assumes a causal link between neuronal energy demand and the regulation of local CBF. The general assumption, which is supported by PET findings showing comparable functional increases in blood flow and glucose uptake (Raichle and Mintun, 2006), is that CBF is coupled to regional glucose utilization, which in turn is directly related to neuronal activity (Magistretti, 2006). Excitatory neuronal activity releases glutamate which activates glia through metabotropic glutamate receptors. The activation of glial cells will induce at the same time an increase in the diameter of nearby blood vessels and stimulation of glucose uptake. In this metabolic hypothesis, the activity-dependent regulation of local CBF is a feedback mechanism that does not anticipate possible demand.

The metabolic hypothesis was supported by the original observation by Zonta et al. (2003) that astrocytic endfeet surrounding brain blood vessels were releasing vasodilating substances; since then other observations have shown that astrocytes could also provoke vasoconstrictions. These opposite observations were confirmed: activation of astrocytes triggers the formation of arachidonic acid that is either converted to 20-hydroxyeicosatetraenoic acid (20-HETE) in smooth muscle causing vasocontraction or to prostaglandin $\mathrm{E}_{2}\left(\mathrm{PGE}_{2}\right)$ causing vasodilation. These intriguing findings are now explained in an elegant paper of MacVicar's group where they demonstrate that in slices, the final fate of arachidonic acid is guided to the vasodilator $\mathrm{PGE}_{2}$ if oxygen levels are low and to vasoconstrictor 20-HETE if oxygen levels are high (Gordon et al., 2008).

The importance given to $\mathrm{p}_{\mathrm{O} 2}$ by this work on astrocytes in brain slices is puzzling. It is known since the 1986 work of Fox and Raichle (1986) that the increase in CBF induced by brain activation is not correlated with $\mathrm{O}_{2}$ metabolism; indeed when neuronal activity increases locally in the brain, regional blood flow increases more than oxygen consumption. Changing experimentally $\mathrm{pO}_{2}$ does not affect regional increase in CBF during brain activation. Mintun et al. (2001) demonstrated in human volunteers that the regional increase in CBF during visual activation was not affected by hypoxia. More recently Leithner et al. (2005) have shown that in the rat, hyperbaric hyperoxygenation did not affect the regional increase of $\mathrm{CBF}$ induced by functional activation. Anyway relevant or not to the physiological control of CBF, the work of MacVicar's group has resolved the apparent opposite effect observed in slices after the activation of astrocytes.

In contrast with the metabolic feedback hypothesis, the neurogenic hypothesis (Estrada and DeFelipe, 1998; Hamel, 2006) describes a feedforward mechanism where the hyperaemia evoked by cerebral activation is linked to synaptic signalling rather than to the metabolic needs of the tissue. The neurogenic hypothesis was highlighted recently by Sirotin and Das (2009) who have found a large haemodynamic signal that could deliver arterial blood to the sensory cortex in anticipation of an increase of local neuronal activity. In short plumbing could precede wiring.

In alert behaving monkeys, Sirotin and Das have developed a task that minimized visual input while preserving trial timing. In a dark room, the animals were required to fix their gaze periodically on a tiny fixation point to get a reward. Intrinsic signal optical imaging and LFP were monitored in the primary visual cortex while the animals performed this task. Even though monkeys were in virtually total darkness with no exposure to visual stimuli, they expressed robust unexpected haemodynamic signals in the visual cortex at the trial frequency. Then, while the animals performed the same fixation task, vigorous visual stimuli were presented; this visual stimuli added a second distinct component to the haemodynamic 
signal. The component generated by visual stimuli was associated with strong LFP. The other vascular signal related to task structure was not accompanied by changes in electrical activities. It is interpreted by the authors as an anticipatory haemodynamic signal that could prime the visual cortex for the expected subsequent strong visual stimuli. The existence of electrical anticipatory signals preceding expected stimuli in the cortex is not new; anticipatory signals were described as early as 1964 by Walter et al. (1964) and reviewed recently by Moore and Cao (2008).

The findings of anticipatory increase in blood flow cannot be explained by the metabolic hypothesis assuming a link between neuronal energy demand and local CBF. These results support the existence of a neuronal network involved in the control of cerebral arteries. The anatomy of the neurovascular net controlling intracerebral blood vessels is expected to be complex with interplay between neurons, glia and vascular smooth muscle cells. This neurovascular unit includes pericytes which are specialised cerebral smooth muscle cells, and several different interneurons containing nitric oxide synthase and various neuropeptides (Cauli et al., 2004; Estrada and DeFelipe, 1998; Hamel, 2006; Rancillac et al. 2006).

The debate among neuroscientists between "metabolic" versus "neurogenic" for the control of CBF has received support in favour of the neurogenic hypothesis in the recent report of Devor et al. (2008), that addressed the relationship between blood flow and glucose consumption in rat primary somatosensory cortex in vivo. Devor et al. examined neuronal and haemodynamic changes and glucose uptake in response to unilateral forepaw stimulation. In contrast to the contralateral forepaw area, where neuronal activity, blood flow and glucose uptake increased in unison, they observed, in the ipsilateral cortex, a blood flow decrease in the presence of increased glucose uptake. Electrophysiological recordings revealed an increase in ipsilateral electrical activity consistent with the observed increase in glucose uptake. The decrease in blood flow in the presence of an increase in glucose uptake in the ipsilateral cortex contradicts the prominent metabolic hypothesis regarding the regulation of $\mathrm{CBF}$, which postulates that energy consumption determines the regional blood flow through the production of vasoactive metabolites. In brief fuelling and plumbing are not always correlated.

In a recent magistral review Logothetis (2008) has described in details the pros and cons of fMRI-BOLD for visualising brain activation. The general consensus is that BOLD is most of the time an excellent surrogate measure of neuronal activity and metabolism. The two recent papers (Devor et al., 2008; Sirotin and Das, 2009) reviewed in the present general commentary indicate that fMRI-BOLD could not always be coupled to neuronal electrical activity nor to metabolism. The intrinsic BOLD signal is directly linked to cerebral blood vessels dilation or contraction by smooth muscles. The control of those seems to be neurogenic making BOLD signalling an exquisite measure of the neuronal control of cerebral blood vessels.

\section{REFERENCES}

Cauli, B., Tong, X. K., Rancillac, A., Serluca, N., Lambolez, B., Rossier, J., and Hamel, E. (2004). Cortical GABA interneurons in neurovascular coupling: relays for subcortical vasoactive pathways. J. Neurosci. 41, 8940-8949.

Devor, A., Hillman, E. M., Tian, P., Waeber, C., Teng, I. C., Ruvinskaya, L., Shalinsky, M. H., Zhu, H., Haslinger, R. H., Narayanan, S. N., Ulbert, I., Dunn, A. K., Lo, E. H., Rosen, B. R., Dale, A. M., Kleinfeld, D., and Boas, D. A. (2008). Stimulusinduced changes in blood flow and 2-deoxyglucose uptake dissociate in ipsilateral somatosensory cortex. J. Neurosci. 28, 14347-14357.

Estrada, C., and DeFelipe, J. (1998). Nitric oxideproducing neurons in the neocortex: morphological and functional relationship with intraparenchymal microvasculature. Cereb. Cortex 8, 193-203.

Fox, P. T., and Raichle M. E. (1986). Focal physiological uncoupling of cerebral blood flow and oxidative metabolism during somatosensory stimulation in human subjects. Proc. Natl. Acad. Sci. USA 83, 1140-1144.

Gordon, G. R. C., Choi, H. B., Rungta, R. L., EllisDavies, G. C. R., and MacVicar, B. A. (2008). Brain metabolism dictates the polarity of astrocyte control over arterioles. Nature 456, 745-750.

Hamel, E. J. (2006). Perivascular nerves and the regulation of cerebrovascular tone. J. Appl. Physiol. 100, 1059-1064.

Leithner, C., Sellien, H., Rohrer, B., Royl, G., Megow, D., Steinbrink, J., Kohl-Bareis, M., Dirnagl, U., and Lindauer, U. (2005). Allosteric release of nitric oxide from haemoglobin does not mediate neurovascular coupling. J. Cereb. Blood Flow Metab. 25, S207.

Logothetis, N. K. (2008). What we can do and what we cannot do with fMRI. Nature 453, 869-878.

Magistretti, P. J. (2006). Neuron-glia metabolic coupling and plasticity. J. Exp. Biol. 209, 2304-2311.

Mintun, M. A., Lundstrom, B. N., Snyder, A. Z., Vlassenko, A. G., Shulman, G. L., and Raichle, M. E. (2001). Blood flow and oxygen delivery to human brain during functional activity: theoretical modelling and experimental data. Proc. Natl. Acad. Sci. USA 98, 6859-6864.

Moore, C. I., and Cao, R. (2008). The hemo-neural hypothesis: on the role of blood flow in information processing. J. Neurophysiol. 99, 2035-2047.

Raichle, M.E., and Mintun, M.A. (2006). Brain work and brain imaging. Annu. Rev. Neurosci. 29, 449-476.

Rancillac, A., Rossier, J., Guille, M., Tong, X. K., Geoffroy, H., Amatore, C., Arbault, S., Hamel, E., and Cauli, B. (2006). Glutamatergic control of microvascular tone by distinct GABA neurons in the cerebellum. J. Neurosci. 26, 6997-7006.

Sirotin, Y. B., and Das, A. (2009). Anticipatory haemodynamic signals in sensory cortex not predicted by local neuronal activity. Nature 457, 475-479.

Walter,D.W., Cooper, R.,Aldridge, V.G., McCallum, W. C., and Winter, A. L. (1964). Contigent negative variation: an electric sign of sensori-motor association and expectancy in the human brain. Nature 203, 380-384.

Zonta, M., Angulo, M. C., Gobbo, S., Rosengarten, B., Hossmann, K. A., Pozzan, T., and Carmignoto, G. (2003). Neuron-to-astrocyte signaling is central to the dynamic control of brain microcirculation. Nat. Neurosci. 6, 43-50.

Received: 21 January 2009; published: 24 February 2009 Citation: Rossier J (2009) Wiring and plumbing in the brain. Front. Hum. Neurosci. 3:2. doi: 10.3389/neuro.09.002.2009

Copyright: (C) 2009Rossier. This is an open-access publication subject to an exclusive license agreement between the authors and the Frontiers Research Foundation, which permits unrestricted use, distribution, and reproduction in any medium, provided the original authors and source are credited. 